\title{
Psychometric properties of the contextual body image questionnaire for athletes: a replication and extension study in female collegiate athletes
}

\author{
Tiffany Stewart $^{1 *}$ D, Lisa Kilpela ${ }^{2}$, Nicole Wesley ${ }^{1}$, Kate Baule ${ }^{1}$ and Carolyn Becker ${ }^{3}$
}

\begin{abstract}
Background: Although the link between body dissatisfaction and eating disorder (ED) pathology is well-established in general female samples, less is known about contextual body image (CBI) among female athletes. $\mathrm{CBI}$ refers to female athletes' body image concerns in two contexts: sport and daily life. The Contextual Body Image Questionnaire for Athletes (CBIQA) measures four dimensions of body image (Appearance, Thin-Fat Self-Evaluation, Thin-Fat Others' Evaluation, and Muscularity) in both contexts. In a sample of female collegiate athletes, this study sought to A) investigate the psychometric properties of the CBIQA, B) examine the cross-sectional relation of CBI with ED pathology and negative affect, and C) assess the degree to which CBI prospectively predicts ED pathology and negative affect.

Method: Using self-report data collected from a multi-site parent trial, we examined the psychometric properties of the CBIQA by confirmatory factor analysis. We assessed construct and criterion validity via cross-sectional bivariate correlation analyses with thin-ideal internalization, negative affect, and ED pathology. Using data from Time 1 and 6 months later (Time 2), we investigated the degree to which CBI prospectively predicted ED pathology and negative affect.

Results: Results from the CFA largely confirmed de Bruin et al.'s (2011) original factor analysis. Two CBIQA dimensions (Thin-Fat Self and Appearance) in both contexts correlated with ED pathology and negative affect. Thin-Fat Others also correlated with ED pathology in both contexts and negative affect in the sport context. The Muscularity dimension was predominantly orthogonal with other measures. CBIQA dimensions were uncorrelated with thin-ideal internalization. When controlling for BMI and Time 1 scores, daily life and sport appearance concerns predicted ED pathology, whereas perceived evaluation of thin-fat by others in the sport context predicted negative affect 6 months later.
\end{abstract}

(Continued on next page)

\footnotetext{
* Correspondence: tiffany.stewart@pbrc.edu

${ }^{1}$ Pennington Biomedical Research Center, Baton Rouge, LA, USA

Full list of author information is available at the end of the article
}

(c) The Author(s). 2021 Open Access This article is licensed under a Creative Commons Attribution 4.0 International License, which permits use, sharing, adaptation, distribution and reproduction in any medium or format, as long as you give appropriate credit to the original author(s) and the source, provide a link to the Creative Commons licence, and indicate if changes were made. The images or other third party material in this article are included in the article's Creative Commons licence, unless indicated otherwise in a credit line to the material. If material is not included in the article's Creative Commons licence and your intended use is not permitted by statutory regulation or exceeds the permitted use, you will need to obtain permission directly from the copyright holder. To view a copy of this licence, visit http://creativecommons.org/licenses/by/4.0/. The Creative Commons Public Domain Dedication waiver (http://creativecommons.org/publicdomain/zero/1.0/) applies to the data made available in this article, unless otherwise stated in a credit line to the data. 
(Continued from previous page)

Conclusions: Results support the psychometric validity of the CBIQA and suggest that it captures variance discrete from thin-ideal internalization. The Muscularity dimension largely was not related to other outcomes. Further, specific elements of perceived self- and other-evaluation in both contexts is relevant to risk for ED pathology and negative affect. Future research could examine the impact of dual body image between sports seasons and after transitioning out of sport.

Clinical trials registration: NCT01735994.

Keywords: Body image, Athletes, Sports, Eating disorders, Depression

\section{Plain English summary}

Female athletes evaluate their bodies in two separate contexts, based on their identities in their sport and daily life: this is called contextual body image (CBI). The Contextual Body Image Questionnaire for Athletes (CBIQA) measures four specific elements of CBI among athletes. This study found that the CBIQA measures its intended four elements of CBI, and that it measures an aspect of body image that is different from traditional thin-ideal internalization. Except for evaluation of Muscularity, the elements of CBI were also related to eating disorder measures. Lastly, taking into account earlier scores on the two outcomes (eating disorder behaviors and negative mood), appearance concerns in both daily life and sport predicted eating disorder symptoms 6 months later. Only perceived evaluation of being fat in sport predicted negative mood 6 months later. Our findings suggest that the CBIQA is measuring body image elements that are unique from other types of body image measures, but are still related to eating disorder symptoms, among female competitive athletes. More research is needed to better understand how athletes are affected by body image concerns in both contexts of their identity.

\section{Introduction}

Contextual body image (CBI) refers to the dual nature of female athlete body image, which consists of body image in sport and in everyday life [1]. Body dissatisfaction has been identified as a significant risk factor for numerous negative outcomes (e.g., depression, eating disorders (ED), unhealthy weight control behaviors) in nonathletic populations [2, 3]; yet the association of CBI with negative outcomes has received less attention. One challenge in studying CBI has been the lack of a wellestablished measure. Recently developed by de Bruin and colleagues [1], the Contextual Body Image Questionnaire for Athletes (CBIQA) assesses various aspects of body image within these two contexts (i.e., sport and daily life). In the only validation study to date, de Bruin et al. [1] found that the CBIQA assessed four dimensions for each of two body image contexts (i.e., sport and daily life). The sport body image context refers to body evaluation within athletic circumstances whereas the daily life body image context refers to body evaluation in everyday life. The four dimensions in both of these body image contexts assess the following: (1) "Appearance" - Evaluation of appearance (ugly to beautiful); (2) "Muscularity" - Level of muscularity (unmuscular to muscular); (3) "Thin-Fat Self" - Self-evaluation of shape/weight/fat (thin/low to fat/high); and (4) "Thin-Fat Others" - Perceived opinions of others on shape/weight/fat (thin/low to fat/high). For the "Appearance" dimension, participants rate themselves from "very ugly" to "very beautiful". For "Muscularity", participants rate the muscularity of their body from "much too unmuscular" to "much too muscular" compared to others. For "Thin-Fat Self", participants rate their body weight and body fat percentage from "much too low" to "much too high". Finally, for "Thin-Fat Others", participants rate whether others thought their body weight and body fat percentage was too low, too high, or neither.

Results from the de Bruin validation study also indicated that all four dimensions in the sport context crosssectionally correlated with the total score from the Eating Disorder Examination Questionnaire (EDE-Q). For the daily life context, both the Appearance and Thin-Fat Self dimensions correlated with the EDE-Q total score. One limitation of this additional set of analyses, however, was that they were conducted in a relatively small sample $(N=52)$ of elite female athletes (i.e., competing at the national or international level) whose sports tend to emphasize leanness (e.g., aesthetic or distance sports). Thus, it is unclear to what degree these findings would generalize to a larger, more inclusive, sample of female athletes.

The aim of the present study was to further investigate the psychometric properties of the CBIQA and to investigate its prospective relation to negative outcomes using data collected as a part of a larger, multi-site, randomized controlled trial, the Female Athlete Body (FAB) 
Project (baseline $N=481$ : [NIMH 1 RO1 MH09444801]). Female collegiate athletes at four different universities in the United States completed the CBIQA at 12 months $(n=380)$ and 18 months $(n=347)$ after randomization into the main $\mathrm{FAB}$ trial. The objectives of this study were to investigate (1) the psychometric properties of the CBIQA (2) the relationship of CBIQA contexts and dimensions to eating disorder pathology, thin-ideal internalization, and negative affect, and (3) assess the degree to which CBI prospectively predicts ED pathology and negative affect in female collegiate athletes. Hypotheses included: (1) the psychometric properties of the CBIQA would be replicated in our sample, (2) CBIQA dimensions in both contexts (sport and daily life) would demonstrate construct validity at the factor level (i.e., factor validity) convergent with measures of body image (thin-ideal internalization and weight/shape concerns) and would demonstrate concurrent criterion validity with measures of theorized correlates (ED pathology and negative affect), and (3) CBIQA would prospectively predict ED pathology and negative affect 6 months later, thus demonstrating predictive criterion validity.

\section{Methods}

\section{Study design}

The parent study included a four-university, three-site parallel-group randomized control trial comparing the FAB group to a waitlist control group [4]. The FAB group participated in an intervention delivered over 3 weeks and broken into three, 80-min sessions led by their peers. FAB is an interactive, small-group, 3-session manualized intervention that encourages participants to strive for the athlete-specific healthy ideal (defined as the way one's body appears when one is appropriately striving to simultaneously maximize physical and mental health, quality of life, and athletic performance) instead of an idealized body appearance. Main components of FAB include a focus on the healthy-ideal versus societal and sport-specific thin-ideals, the Female Athlete Triad, nutrition, sleep, and healthy exercise, goal setting, and body image exercise [4]. The waitlist control group received a Female Athlete Triad brochure at the beginning of the study. Data were collected at baseline, 3 weeks (post-intervention for the FAB group), 6 months, 12 months, and 18 months for both groups. For more detailed information on study design, baseline data, and main outcomes, please see Stewart et al. $[4,5]$.

\section{Ethics}

The study was monitored and approved by the Institutional Review Board (IRB) of the coordinating center at Pennington Biomedical Research Center (Baton Rouge, LA). Each partner site had IRB approval as well. Participants provided informed consent and those under the age of 18 also provided assent. Each participant earned compensation based on completing a packet of questionnaires that included the measures of focus in this paper (\$20) and phone interviews (\$30) at five time points for a possible total of $\$ 250$ earned from this study. These incentives were in line with National Collegiate Athlete Association (NCAA) guidelines and provided motivation to student athletes constricted by time and responsibilities. A data and safety monitoring board provided study oversight.

\section{Recruitment}

Participants included female athletes at each university within the ages of 17-27 years (mean age at baseline for the parent study $=19$ years); mean BMI at 12 -month follow-up (Time 1 for this study) was 22.70 ( $\mathrm{SD}=2.91$ ).

Study staff worked with the athletic training staff at the university athletic departments to identify the athletic teams who would participate in the study. Additional team meetings were scheduled outside of the athletes' regularly scheduled team meetings for the sole purpose of study staff meeting with athletes about participation in the study. Thus, study staff recruited participants in the absence of athletics staff at team meetings to limit potential coercion. Study staff informed athletes that study participation was anonymous and voluntary (see Stewart et al.,4, for details). To further reduce coercion, athletes were informed that coaches and athletics staff would not know which athletes participated or declined in the study.

The majority of participants reported White race (81\%); $14.8 \%$ reported Black race and 13.1\% endorsed Hispanic ethnicity. Study enrollment began in August 2012 and completed in October 2014.

\section{Procedure}

As noted above, data for the current study are a part of the larger, parent study. For the parent study, participation in the FAB intervention program was separate from participation in the study (questionnaires and phone interviews) because the athletic departments wanted all athletes to participate in the program. Thus, all athletes participated in the program unless granted an excused absence by athletics staff, but only those who consented to participate in the research study completed the questionnaires and phone interviews. Athletes were allowed to drop out of the study at any time, consistent with similar trials conducted previously [6]. Follow-up data collection was conducted at set times for each group and participants who could not attend completed measures either individually with study staff or electronically via email. Some data were lost to follow-up and those participants were recorded as missing only for that time 
point, as some participants returned at later follow-up points.

The CBIQA was introduced at the 12- and 18-month follow-up time points of the parent study. For the purposes of this study, data collected at 12-month follow-up in the parent trial serve as Time 1 data (baseline), while data collected at 18-month follow-up of the parent trial (i.e., 6 months later) comprise Time 2.

\section{Assessments}

In addition to the measures listed below, we collected demographics and calculated body mass index (BMI) from self-reported height and weight (see Table 1 for descriptive statistics).

\section{Contextual body image}

The Contextual Body Image Questionnaire for Athletes (CBIQA), developed by de Bruin [1], was used to assess the differences in body image in athletes when in sport compared to out of sport. This measure uses a 7-point Likert scale, and has been validated as an appropriate tool to measure both body image contexts in athletes [1]. The CBIQA uses two contexts (daily life and sport), and there are four dimensions within each context

Table 1 12-month (Time 1) and 18-month (Time 2) descriptive statistics

\begin{tabular}{lll}
\hline & $\begin{array}{l}\text { Time } \mathbf{1}(\boldsymbol{N}=\mathbf{3 8 0}) \\
\boldsymbol{M}(\mathrm{SD})\end{array}$ & $\begin{array}{l}\text { Time } \mathbf{2}(\mathbf{N}=\mathbf{3 4 7}) \\
\boldsymbol{M}(\mathbf{S D})\end{array}$ \\
\hline CBIQA Daily Life & & \\
Appearance & $5.15(.89)$ & $5.20(.90)$ \\
Muscle & $4.05(.68)$ & $4.04(.67)$ \\
Thin-fat self & $4.42(.68)$ & $4.41(.71)$ \\
Thin-fat other & $4.02(.61)$ & $4.04(.61)$ \\
CBIQA Sport & & \\
Appearance & $4.97(.98)$ & $4.98(1.01)$ \\
Muscle & $3.81(.66)$ & $3.78(.66)$ \\
Thin-fat self & $4.40(.72)$ & $4.39(.72)$ \\
Thin-fat other & $4.10(.55)$ & $4.11(.61)$ \\
EDE-Q & & $1.07(1.16)$ \\
EDE-Q Res & $1.04(1.19)$ & $.54(.84)$ \\
EDE-Q EC & $.48(.78)$ & $1.09(1.26)$ \\
EDE-Q WC & $1.06(1.16)$ & $1.39(1.31)$ \\
EDE-Q SC & $1.32(1.24)$ & $1.02(1.02)$ \\
EDE-Q Global & $.97(.99)$ & $3.37(.65)$ \\
IBSS-R & $3.39(.65)$ & $1.57(.64)$ \\
PANAS & $1.51(.57)$ & \\
\hline
\end{tabular}

Note: CBIQA Contextual Body Image Questionnaire for Athletes; EDE-Q Eating Disorders Examination - Questionnaire; EDE-Q Res Restraint subscale; EDE-Q EC Eating concerns subscale; EDE-Q WC Weight concerns subscale; EDE-Q SC Shape concerns subscale; EDE-Q Global EDE-Q global score; IBSS-R Ideal Body Stereotype Scale - Revised; PANAS Positive and Negative Affect Schedule, negative affect subscale
(Appearance, Muscularity, Thin-Fat Self, and Thin-Fat Others). Lower scores signify perception as "too ugly" on Appearance and "too unmuscular" on the Muscularity dimension. Higher scores on the Thin-Fat Self and Thin-Fat Others dimensions indicate perceiving one as "too fat." Questions include statements such as "I think my body shape is ..." and "I think the muscularity of my body compared to others is ..." , with participants selecting where they are on the scale.

\section{Eating disorder (ED) pathology}

We used the Eating Disorder Examination Questionnaire (EDE-Q [7];), [8], which evaluates eating attitudes and behaviors over the past 28 days, and higher scores indicate greater pathology. The EDE-Q includes four subscales (restraint, eating concerns, weight concerns, and shape concerns) and a global score. We used the EDE-Q global score to measure overall ED pathology in the predictive models. Past research [9] supports the internal consistency of this measure $(\alpha=.92)$ and test-retest reliability $(r=.90)$. Current sample internal consistency was $\operatorname{good}(\alpha=.92)$.

\section{Thin-ideal internalization}

We used the Ideal-body Stereotype Scale-revised (IBSS$\mathrm{R}$ [10];) to assess internalization of the traditional thinideal. The IBSS-R has demonstrated good internal validity and test-retest reliability in past research, and predictive validity for onset of bulimic symptomatology [9]. Higher scores indicate greater internalization of the thin-ideal, and internal consistency in the current sample was good (Cronbach's $\alpha=.89$ ).

\section{Negative affect}

The sadness, guilt, and fear/anxiety subscales of the Positive and Negative Affect Scale-revised (PANAS-X; 11) assessed negative affect; higher scores indicate greater negative affect. The negative affect subscale of the PANAS has demonstrated good internal consistency in past research [11], and internal consistency in this sample was good (Cronbach's $\alpha=.93$ ).

\section{Statistical analysis}

To test the validity of the results from de Bruin et al. [1], a confirmatory factor analysis (CFA) was conducted with Time 1 (12-month data from the FAB study). The CFA was conducted using SAS 9.4 software (SAS Institute Inc., Cary, NC, USA). We assessed overall model fit for each context using the following parameters: 1 ) model $\mathrm{X}^{2} \quad(p<.05$ indicates good fit); 2$)$ comparative fit index (CFI; CFI $\geq 0.90$ indicates good fit); 3 ) root mean square error of approximation (RMSEA; RMSEA $<0.08$ indicates good fit); and 4) standardized root mean square 
residual (SRMR; SRMR $<0.08$ indicates good fit). Factor loadings of .7 or higher were considered acceptable [12].

We examined construct validity by conducting crosssectional (Time 1 data) bivariate correlation analyses with measures of body image (thin-ideal internalization and the weight and shape concerns subscales of the EDE-Q). We examined concurrent criterion validity with cross-sectional (Time 1 data) bivariate correlation analyses with measures of ED pathology (EDE-Q restraint and eating concerns subscales, global EDE-Q, and negative affect), as ED pathology and negative affect are typically theorized as downstream constructs related to body image disturbances. To adjust for multiple comparisons, we used a cutoff of $p<.01$ as the threshold for significance for the correlation analyses. Finally, to examine the degree to which contextual body image prospectively predicts ED pathology and negative affect 6 months later (i.e., predictive criterion validity), we conducted linear regression models using CBIQA dimensions at Time 1 to predict each outcome at 6 months later (Time 2). For predictive models, we controlled for BMI, which is in line with the de Bruin et al. [1] validation paper, as well as Time 1 scores on each dependent variable. Assumptions for analyses were met. We tested for collinearity among predictor variables using variance inflation factors (VIFs) in each model; VIFs greater than 10 suggest collinearity. We also examined tolerance; tolerance below 0.2 indicates multicollinearity. We did not control for intervention group because we did not see a strong rationale that a $3 \times 80$-min intervention sessions conducted a year earlier would differentially affect the possible predictive relationship between CBI and outcomes. Analyses were completed using SPSS version 26 (IBM SPSS Statistics for Windows, Version 26.0. Armonk, NY: IBM Corp.)

\section{Results}

The ancillary study comprised data from 380 female collegiate athletes with a mean age of 20 years. Results from the CFAs (Time 1 data) largely confirmed de Bruin's original factor analysis [1] with slightly different factor loadings (Tables 2-3). Indicators of overall model fit were mixed for the daily life context $\left(\chi^{2}(84)=536.32\right.$, $p<.001 ; \mathrm{CFI}=0.90 ; \mathrm{RMSEA}=0.10 ; \mathrm{SRMR}=0.06)$ and the sport context $\left(\chi^{2}(84)=727.13, p<.001\right.$; CFI $=0.89$; RMSEA $=0.14 ; \quad S R M R=0.05$ ). Internal consistency in the current sample for all dimensions in the daily life context was good (see Table 2; Cronbach's $\alpha$ range $=$ $.82-.93)$, as was internal consistency for all dimensions in the sport context (see Table 3; Cronbach's $\alpha$ range = .87-.95). All factor loadings were significant at the $p>.0001$ level; factor loadings for items exceeded .7, with the exceptions of body shape as perceived by others and muscularity as perceived by others in the daily life
Table 2 Confirmatory factor analysis with factor loadings for daily life context using 12-month (Time 1) data

\begin{tabular}{|c|c|c|c|c|}
\hline \multirow[t]{2}{*}{ Factors } & \multicolumn{2}{|c|}{ Thin-fat dimension } & \multirow[t]{2}{*}{ Appearance } & \multirow[t]{2}{*}{ Muscularity } \\
\hline & Self & Other & & \\
\hline \multicolumn{5}{|l|}{ CBIQA Daily Life } \\
\hline Appearance $^{a}$ & & & 0.871 & \\
\hline Appearance ${ }^{b}$ & & & 0.842 & \\
\hline Appearance $^{c}$ & & & 0.743 & \\
\hline Body shape $^{a}$ & 0.766 & & & \\
\hline Body shape $^{b}$ & 0.797 & & & \\
\hline Body shape $^{c}$ & & 0.525 & & \\
\hline Muscularity $^{a}$ & & & & 0.777 \\
\hline Muscularity ${ }^{\mathrm{b}}$ & & & & 0.840 \\
\hline Muscularity $^{c}$ & & & & 0.650 \\
\hline Body weight ${ }^{a}$ & 0.801 & & & \\
\hline Body weight $^{b}$ & 0.877 & & & \\
\hline Body weight ${ }^{c}$ & & 0.752 & & \\
\hline Fat percentage ${ }^{a}$ & 0.827 & & & \\
\hline Fat percentage $\mathrm{e}^{\mathrm{b}}$ & 0.861 & & & \\
\hline Fat percentage $e^{c}$ & & 0.803 & & \\
\hline Reliability (a) & 0.934 & 0.887 & 0.883 & 0.822 \\
\hline Variance proportion & $39.44 \%$ & $27.53 \%$ & $20.45 \%$ & $12.51 \%$ \\
\hline
\end{tabular}
Note: ${ }^{a}$ Own perception; ${ }^{\mathrm{b}}$ Own perception compared to others; ${ }^{\mathrm{C}}$ Perceived opinion of others

context (Table 2), and body shape as perceived by others in the sport context (Table 3).

Correlation analyses (Table 4) indicated that Appearance, Thin-Fat Self, and Thin-Fat Other dimensions in both body image contexts (sport and daily life) correlated with EDE-Q weight and shape concerns, suggesting convergent construct validity. Appearance, Thin-Fat Self, and Thin-Fat Other dimensions were correlated with EDE-Q restraint and eating concerns subscales, EDE-Q global score, and negative affect (except Thin-Fat Others in daily life), indicating concurrent criterion validity. Traditional thin-ideal internalization as measured by the IBSS-R largely was orthogonal with all dimensions except Muscularity in sport, which indicated a small negative correlation (i.e., more Muscularity in sport was correlated with lower thin-ideal internalization), suggesting discriminant validity. Only within the sport context did the Muscularity dimension correlate with negative affect; no correlations were significant for Muscularity in the daily life context. Thus, three of the CBIQA dimensions (Appearance, Thin-Fat Self, and Thin-Fat Others) within both body image contexts largely correlated with ED pathology and negative affect, while not with thinideal internalization.

Regarding prospective prediction of ED pathology 6 months later (Table 5), Time 1 daily life and sport 
Table 3 Confirmatory factor analysis with factor loadings for sport context using 12-month (Time 1) data

\begin{tabular}{|c|c|c|c|c|}
\hline \multirow[t]{2}{*}{ Factors } & \multicolumn{2}{|c|}{ Thin-fat dimension } & \multirow[t]{2}{*}{ Appearance } & \multirow[t]{2}{*}{ Muscularity } \\
\hline & Self & Other & & \\
\hline \multicolumn{5}{|l|}{ CBIQA Sport } \\
\hline Appearance $^{a}$ & & & 0.916 & \\
\hline Appearance $^{b}$ & & & 0.919 & \\
\hline Appearance $^{c}$ & & & 0.847 & \\
\hline Body shape ${ }^{a}$ & 0.879 & & & \\
\hline Body shape $^{b}$ & 0.899 & & & \\
\hline Body shape $^{c}$ & & 0.676 & & \\
\hline Muscularity ${ }^{\mathrm{a}}$ & & & & 0.808 \\
\hline Muscularity ${ }^{b}$ & & & & 0.894 \\
\hline Muscularity $^{c}$ & & & & 0.773 \\
\hline Body weight ${ }^{a}$ & 0.842 & & & \\
\hline Body weight ${ }^{b}$ & 0.847 & & & \\
\hline Body weight $^{c}$ & & 0.779 & & \\
\hline Fat percentage ${ }^{a}$ & 0.869 & & & \\
\hline Fat percentage ${ }^{b}$ & 0.879 & & & \\
\hline Fat percentage ${ }^{c}$ & & 0.792 & & \\
\hline Reliability (a) & 0.952 & 0.896 & 0.933 & 0.876 \\
\hline Variance proportion & $40.00 \%$ & $25.75 \%$ & $21.00 \%$ & $14.15 \%$ \\
\hline
\end{tabular}

Appearance dimensions predicted EDE-Q global scores at Time 2 when controlling for Time 1 EDE-Q global scores and BMI. The overall model accounted for $57.3 \%$ (adjusted $\left.\mathrm{R}^{2}\right)$ of the variance $(F(10,301)=41.40$, $p<.001)$. For negative affect, only Time 1 sport Thin-Fat Others predicted negative affect 6 months later (Time 2) when controlling for Time 1 PANAS scores and BMI (Table 6). The overall model predicting negative affect accounted for $37.4 \%$ (adjusted $\mathrm{R}^{2}$ ) of the variance $(F(10$, 304) $=19.19, \quad p<.001) . \quad$ Durbin-Watson statistics indicated no concern for autocorrelation in either model. VIFs were less than 10 and all tolerance statistics were > 0.2 , suggesting no multicollinearity among predictor variables in either model.

\section{Discussion}

Dual body images for female athletes exist for different contexts, both on and off the field. Traditional gender roles and societal perceptions of women's sports uniquely affect female athletes' body image. The femaleathlete paradox refers to the conflict women experience between the feminine ideal in daily life and the muscular ideal in athletic domains [13, 14]. Further, women who play sports that are more sexually objectified (e.g., volleyball, gymnastics, tennis) may experience greater thinideal internalization and body shame [15]. The specific influences of gender, the thin-ideal, and the athletic ideal may be key to understanding how CBI correlates with eating pathology and negative affect.

The aims of the present study were to further investigate both the psychometric properties of the CBIQA and to explore the degree to which constructs assessed by the CBIQA predicted ED pathology and negative affect 6 months later. With regards to the confirmatory factor analysis, results largely replicated those of de Bruin et al. [1] and provide further support for the psychometric validity of the CBIQA. Similar to de Bruin et al. [1], the item inquiring about body shape as perceived by others in the daily life context had the lowest factor loading (Table 2).

de Bruin and colleagues [1] also examined the association of the four dimensions assessed in daily and sport life with global EDE-Q scores. We sought to both replicate and extend these findings by correlating the dimensions in both contexts with both the global score and the EDE-Q subscale scores. With two exceptions, global score findings were replicated. More specifically, both studies found that the Appearance and Thin-Fat Self

Table 4 Cross-sectional correlations of CBIQA domains with key body image constructs $(N=380)$

\begin{tabular}{|c|c|c|c|c|c|c|c|c|}
\hline & \multicolumn{4}{|l|}{ Daily Life } & \multicolumn{4}{|l|}{ Sport } \\
\hline & Appearance & Muscularity & Thin-fat self & Thin-fat other & Appearance & Muscularity & Thin-fat self & Thin-fat other \\
\hline EDEQ Res & $-.232^{* *}$ & .023 & $.443^{* *}$ & $.226^{* *}$ & $-.246^{* *}$ & .027 & $.391^{* *}$ & $.276^{* *}$ \\
\hline EDEQ EC & $-.260^{* *}$ & .059 & $.401^{* *}$ & $.280^{* *}$ & $-.294^{* *}$ & .015 & $.369^{* *}$ & $.339 * *$ \\
\hline EDEQ WC & $-.375^{* *}$ & .016 & $.620^{* *}$ & $.387^{* *}$ & $-.383^{* *}$ & .014 & $.568^{* *}$ & $.428^{* *}$ \\
\hline EDEQ SC & $-.391^{* *}$ & -.021 & $.594^{* *}$ & $.385^{* *}$ & $-.407^{* *}$ & -.029 & $.559^{* *}$ & $.422^{* *}$ \\
\hline EDEQ Global & $-.354^{* *}$ & .017 & $.581^{* *}$ & $.358^{* *}$ & $-.371^{* *}$ & .006 & $.533^{* *}$ & $.408^{* *}$ \\
\hline IBSSR & .059 & -.082 & .053 & -.086 & -.023 & $-.143^{* *}$ & .048 & -.044 \\
\hline PANAS & $-.224^{* *}$ & -.125 & $.222^{* *}$ & .130 & $-.250^{* *}$ & $-.188^{* *}$ & $.226^{* *}$ & $.163^{* *}$ \\
\hline
\end{tabular}

Note: ${ }^{* *}=p<.01$; CBIQA Contextual Body Image Questionnaire for Athletes; EDE-Q Eating Disorders Examination - Questionnaire; EDE-Q Res Restraint subscale; $E D E-Q$ EC Eating concerns subscale; EDE-Q WC Weight concerns subscale; EDE-Q SC Shape concerns subscale; EDE-Q Global EDE-Q global score; IBSS-R Ideal Body Stereotype Scale - Revised; PANAS Positive and Negative Affect Schedule, negative affect subscale 
Table 5 Summary of multiple linear regression predicting ED pathology at 6-month follow-up (Time 2)

\begin{tabular}{llllll}
\hline & B & SE B & B & t value & Sig \\
\hline BMI 12mo & -.019 & .016 & -.053 & -1.168 & .244 \\
EDE-Q 12mo & .656 & .050 & .646 & $\mathbf{1 3 . 1 8 7}$ & $\mathbf{. 0 0 0}$ \\
Daily & & & & & \\
$\quad$ Appearance & $\mathbf{. 1 6 8}$ &. $\mathbf{0 7 4}$ & $\mathbf{. 1 4 5}$ & $\mathbf{2 . 2 6 7}$ & $\mathbf{. 0 2 4}$ \\
$\quad$ Muscle & -.073 & .074 & -.050 & -.985 & .325 \\
Thin-fat self & .052 & .126 & .035 & .411 & .682 \\
Thin-fat other & .046 & .109 & .027 & .419 & .675 \\
Sport & & & & & \\
$\quad$ Appearance & -.206 & .066 & -.200 & $-\mathbf{3 . 1 1 8}$ & $\mathbf{. 0 0 2}$ \\
Muscle & .097 & .077 & .064 & 1.255 & .210 \\
Thin-fat self & .023 & .111 & .016 & .208 & .836 \\
Thin-fat other & .180 & .118 & .101 & 1.526 & .128 \\
\hline
\end{tabular}

Note: Bold indicates statistical significance at $a=0.05 ; B M I$ Body mass index; EDE-Q Eating Disorders Examination-Questionnaire global score; $12 \mathrm{mo}=$ data collected at 12-month follow-up in the parent trial, comprising Time 1 in the current study; Durbin-Watson test of autocorrelation $=1.8$; VIFs ranged from $1.0-5.1$; all tolerance values $<0.2$

dimensions in both contexts correlated with EDE-Q global scores and that daily life Muscularity did not. Findings differed with regards to daily life Thin-Fat Others, which correlated in our study but not de Bruin et al., and sport Muscularity, which correlated in de Bruin, but not our study. One explanation for this may be related to the different nature of our samples as de Bruin's study comprised more elite athletes, as well as a wider age range (age 11-27), than our sample of collegiate athletes (age 18-21). Further, de Bruin specifically recruited high

Table 6 Summary of multiple linear regression predicting negative affect at 6-month follow-up (Time 2)

\begin{tabular}{llllll}
\hline & $\mathbf{B}$ & SE B & $\boldsymbol{B}$ & $\boldsymbol{t}$ value & Sig \\
\hline BMI 12mo & -.001 & .012 & -.003 & -.059 & .953 \\
PANAS 12mo & $\mathbf{. 5 9 1}$ &. $\mathbf{0 5 0}$ & $\mathbf{. 5 7 2}$ & $\mathbf{1 1 . 7 1 9}$ & $\mathbf{. 0 0 0 ^ { * }}$ \\
Daily & & & & & \\
$\quad$ Appearance & -.007 & .054 & -.010 & -.128 & .898 \\
Muscle & -.066 & .054 & -.074 & -1.214 & .226 \\
Thin-fat self & -.031 & .088 & -.035 & -.353 & .724 \\
$\quad$ Thin-fat other & -.087 & .080 & -.084 & -1.077 & .282 \\
Sport & & & & & \\
$\quad$ Appearance & -.029 & .048 & -.046 & -.596 & .552 \\
$\quad$ Muscle & .012 & .057 & .013 & .218 & .827 \\
$\quad$ Thin-fat self & .020 & .081 & .024 & .249 & .803 \\
$\quad$ Thin-fat other & $\mathbf{. 1 7 6}$ & $\mathbf{. 0 8 6}$ & $\mathbf{. 1 6 1}$ & $\mathbf{2 . 0 5 0}$ & $\mathbf{. 0 4 1 *}$ \\
\hline
\end{tabular}

Note: Bold indicates statistical significance at $a=0.05 ; B M I$ Body mass index; PANAS Positive and Negative Affect Schedule negative affect subscale; $12 \mathrm{mo}=$ data collected at 12-month follow-up in the parent trial, comprising Time 1 in the current study; Durbin-Watson test of autocorrelation $=2.0$; VIFs ranged from 1.0-4.8; all tolerance values $<0.2$ performance women athletes with disordered eating, whereas our sample had very low rates of disordered eating.

With regard to EDE-Q subscale scores, which were not examined in de Bruin, all dimensions except Muscularity correlated with all subscales in both contexts. Within the Appearance dimension, viewing yourself (and perceiving others' opinions of yourself) as ugly was related to higher levels of ED pathology in both the daily life and sport contexts. Self-evaluation and perceived other-evaluation as fatter were also related to more ED pathology. Overall, CBIQA dimensions except Muscularity demonstrated construct validity with the weight and shape concerns subscales of the EDE-Q, as well as concurrent criterion validity with ED pathology and negative affect.

Contrary to our hypothesis, traditional thin-ideal internalization was orthogonal to all dimensions except Muscularity in sport, suggesting that the CBIQA is largely tapping into a construct distinct from traditional thin-ideal internalization. Higher Muscularity in sport was associated with lower negative affect and less thinideal internalization. Muscularity in daily life appears to be tapping a different construct and was not related to ED pathology, thin-ideal internalization, or negative affect. It was also not predictive of negative outcomes at 6-month follow-up.

In daily life, perceiving oneself as too ugly and too fat was related to higher negative affect. In sport, viewing oneself as uglier, too unmuscular, and too fat (self and other) was related to higher negative affect. Interestingly, lower Muscularity and higher ratings of Thin-Fat Others' opinions correlated with higher negative affect in the sport context but not in daily life. Muscularity and how others perceive your body may play a larger role in sport than in daily life; the pressures associated with how one's body is perceived may lead to feeling worse about oneself. The "muscular ideal" and its psychological impact has been studied in men [16], but less so in women. Women show a drive for muscularity much like men, but may be more focused on achieving muscle tone than muscle mass [17].

In addition, the sport setting may particularly emphasize muscle tone and the opinions of others (such as teammates, coaches, and parents) about athletes' bodies [18]. Feeling criticized or stigmatized in sport (Thin-Fat Others' opinions) due to body shape and size could affect one's perception of oneself in the sport overall, which may account for greater negative affect [19]. Despite the association between higher Muscularity and more negative affect, our findings also revealed a small negative correlation between Muscularity in sport and thin-ideal internalization. Athletes who view themselves with higher Muscularity may have less of a drive toward the traditional 
thin-ideal. In summary, muscularity may be a unique dimension for female athletes that warrants closer examination.

CBIQA scores related to Appearance may predict future ED pathology and negative affect, indicating predictive criterion validity. Therefore, this measure may be helpful in screening for future issues with disordered eating and depression. An athlete-specific screening tool could be useful for preventing and addressing EDs in this population [20]. Further research on contextual body image is needed to evaluate the impact of these dual body images with female athletes-not only while in sport, but while away or retiring from sport, including periods of injury, between seasons and when completing sport.

Strengths of this study include strong internal consistency for all assessments, a large sample, a follow-up time point 6 months later, and the inclusion of prospective analysis to inform about criterion validity. Limitations of the study include reliance on self-report data, attrition at follow-up, and that the CBIQA was delivered to participants 12 months into the $\mathrm{FAB}$ program as opposed to the beginning of the parent trial.

\section{Conclusions}

A dual body image exists for female collegiate athletes. In daily life and in sport, different dimensions of body image (Appearance, Muscularity, Thin-Fat Self, and Thin-Fat Others) correlate with ED pathology and negative affect. In both contexts, all dimensions of body image except for Muscularity correlate with more ED pathology. In the sport context, Muscularity and ThinFat Others' opinions may play a more salient role. Appearance-related scores could be used in a screening tool for athletes to predict future disordered eating and depression. This study provides insight into the specific nature of female athlete body image in order to suggest new preventative measures (in terms of EDs and depression) for this population.

\section{Abbreviations}

BMI: Body mass index; CBI: Contextual body image; CBIQA: Contextual body image questionnaire for athletes; ED: Eating disorder; EDE-Q: Eating disorder examination questionnaire; FAB: Female athlete body project; IBSS-R: Idealbody stereotype scale-revised; IRB: Institutional review board; NCAA: National collegiate athlete association; NIMH: National institute of mental health; PANAS-X: Positive and negative affect scale-revised

\section{Acknowledgements}

Not applicable.

\section{Authors' contributions}

$\mathrm{CB}$ and TS designed the study and disseminated CBIQA questionnaires to athletes as part of the FAB trial. LK analyzed and interpreted the athletes' CBIQA data, and was a major contributor in writing the manuscript. NW and $\mathrm{KB}$ assisted with writing and revising the manuscript. All authors read and approved the final manuscript.

\section{Authors' information}

Not applicable.

\section{Funding}

The FAB Project was funded by a National Institute of Mental Health (NIMH) R01 grant ([NIMH 1 RO1 MH094448-01]). The only role of the NIMH was providing funding for the study.

\section{Availability of data and materials}

The datasets used and/or analyzed during the current study are available from the corresponding author on reasonable request.

\section{Declarations}

Ethics approval and consent to participate

All participants provided consent to participate. Athletes were informed that participation in the study was both anonymous and voluntary [4]. The study was monitored and approved by the IRB at Pennington Biomedical Research Center. A data and safety monitoring board also provided study oversight.

Consent for publication

Not applicable.

\section{Competing interests}

None to disclose.

\section{Author details}

${ }^{1}$ Pennington Biomedical Research Center, Baton Rouge, LA, USA. ${ }^{2}$ UT Health San Antonio, San Antonio, TX, USA. ${ }^{3}$ Trinity University, San Antonio, TX, USA.

Received: 27 August 2020 Accepted: 22 April 2021

Published online: 05 May 2021

References

1. de Bruin AP, Oudejans RRD, Bakker FC, Woertman L. Contextual body image and athletes' disordered eating: the contribution of athletic body image to disordered eating in high performance women athletes. Eur Eat Disord Rev. 2011;19(3):201-15. https://doi.org/10.1002/erv.1112.

2. Stice E, Shaw HE. Role of body dissatisfaction in the onset and maintenance of eating pathology: a synthesis of research findings. J Psychosom Res. 2002;53(5):985-93. https://doi.org/10.1016/S0022-3999(02)00488-9.

3. Ward RM, Hay M.C. Depression, coping, hassles, and body dissatisfaction: Factors associated with disordered eating. Eat Behav 2015; 17: 14-18. Available from: https://doi.org/10.1016/j.eatbeh.2014.12.002.

4. Stewart T, Pollard T, Hildebrandt T, Beyl R, Wesley N, Kilpela LS, et al. The female athlete body (FAB) study: rationale, design, and baseline characteristics. Contemp Clin Trials. 2017;60:63-71. https://doi.org/10.1016/j. cct.2017.06.005.

5. Stewart T, Pollard T, Hildebrandt T, Wesley NY, Kilpela LS, \& Becker CB. The female athlete body project study: 18-month outcomes in eating disorder symptoms and risk factors. Int J Eat Disord 2019: 1-10. Available from https://doi.org/10.1002/eat.23145, 52, 11

6. Becker CB, McDaniel L, Bull S, Powell M, McIntyre K. Can we reduce eating disorder risk factors in female college athletes? A randomized exploratory investigation of two peer-led interventions. Body Image 2012; 9(1):31-42. Available from: https://doi.org/https://doi.org/10.1016/j.bodyim.2011.09.005.

7. Fairburn CG, Beglin SJ. Assessment of eating disorders: Interview or selfreport questionnaire? Int J Eat Disord 1994; 16(4): 363-370. Available from: https://doi.org/10.1002/1098-108X(199412)16:4<363::AID-EAT2260160405>3. $0 . \mathrm{CO} ; 2$.

8. Fairburn CG. Cognitive behavior therapy and eating disorders. New York: Guilford Press; 2008

9. Stice E., Shaw H., Burton E., Wade E. Dissonance and healthy weight eating disorder prevention programs: a randomized efficacy trial. J Consult Clin Psychol 2006;74(2):263-275. https://doi.org/10.1037/0022-006X.74.2.263.

10. Stice E, Fisher M, Martinez E. Eating disorder diagnostic scale: Additional evidence of reliability and validity. Psychol Assess 2004; 16(1): 60-71. Available from: https://doi.org/10.1037/1040-3590.16.1.60.

11. Watson D, Clark LA, Tellegen A. Development and validation of brief measures of positive and negative affect: The PANAS scales. J Pers Soc 
Psychol 1988; 54(6): 1063-1070. Available from: https://doi.org/10.1037/ 0022-3514.54.6.1063.

12. Hair JF, Black WC, Babin BJ, Anderson RE, Tatham RL. Multivariate data analysis, vol. 7. 7th ed. NJ: Pearson prentice hall upper Saddle River; 2009.

13. Krane V, Choi PYL, Baird SM, Aimar CM, Kauer KJ. Living the paradox: female athletes negotiate femininity and muscularity. Sex Roles J Res. 2004 Mar; 50(5-6):315-29. https://doi.org/10.1023/B:SERS.0000018888.48437.4f.

14. Ross SR, Shinew KJ. Perspectives of women college athletes on sport and gender. Sex Roles J Res. 2008 Jan;58(1-2):40-57. https://doi.org/10.1007/ s11199-007-9275-4.

15. Varnes JR, Stellefson ML, Miller MD, Janelle CM, Dodd V, Pigg RM. Body esteem and self-objectification among collegiate female athletes: does societal objectification make a difference? Psychol Women Q. 2015 Mar 1; 39(1):95-108. https://doi.org/10.1177/0361684314531097.

16. Cafri G, Kevin Thompson J, Ricciardelli L, McCabe M, Smolak L, Yesalis C Pursuit of the muscular ideal: physical and psychological consequences and putative risk factors. Clin Psychol Rev. 2005;25(2):215-39. https://doi.org/10.1 016/j.cpr.2004.09.003.

17. Kyrejto JW, Mosewich AD, Kowalski KC, Mack DE, Crocker PRE. Men's and women's drive for muscularity: gender differences and cognitive and behavioral correlates. J Sport Exercise Psy 2008;6:69-84. Available at: http://dx. doi.org.libezp.lib.lsu.edu/https:/doi.org/10.1080/1612197X.2008.9671855, 1

18. Cosh S, Tully PJ, Crabb S. Discursive practices around the body of the female athlete: An analysis of sport psychology interactions in elite sport. Psychol Sport Exerc 2019; 43: 90-104. Available from: https://doi.org/10.101 6/j.psychsport.2018.12.021.

19. Essayli JH, Murakami JM, Wilson RE, Latner JD. The impact of weight labels on body image, internalized weight stigma, affect, perceived health, and intended weight loss behaviors in normal-weight and overweight college women. Am J Health Promot. 2017;31(6):484-90. https://doi.org/10.1177/ 0890117116661982.

20. Wagner AJ, Erickson CD, Tierney DK, Houston MN, Bacon CEW. The diagnostic accuracy of screening tools to detect eating disorders in female athletes. J Sport Rehabil. 2016;25(4):395-8. https://doi.org/10.1123/jsr.20140337.

\section{Publisher's Note}

Springer Nature remains neutral with regard to jurisdictional claims in published maps and institutional affiliations.

Ready to submit your research? Choose BMC and benefit from:

- fast, convenient online submission

- thorough peer review by experienced researchers in your field

- rapid publication on acceptance

- support for research data, including large and complex data types

- gold Open Access which fosters wider collaboration and increased citations

- maximum visibility for your research: over $100 \mathrm{M}$ website views per year

At $\mathrm{BMC}$, research is always in progress.

Learn more biomedcentral.com/submissions 